\title{
Relation of spirometric function to radiographic interstitial fibrosis in two large workforces exposed to asbestos: an evaluation of the ILO profusion
}

\author{
score
}

\author{
Albert Miller, Ruth Lilis, James Godbold, Xiaochu Wu
}

\begin{abstract}
Objectives-To analyse quantitatively the relations of spirometric lung function (forced vital capacity (FVC)) to radiographic interstitial pulmonary fibrosis (assessed by the International Labour Organisation (ILO) profusion score of small irregular opacities) in two large workforces exposed to different intensities of asbestos. These analyses consider the question whether a similar profusion score in differently exposed workers is associated with a similar effect on lung function.
\end{abstract}

Methods-Surveys of two workforces, insulators $(n=2611)$ and sheet metal workers $(n=1245)$, by the same investigators allowed comparison of the effects of the two levels of exposure to asbestos. The two groups were of similar age and had similar percentages of non-smokers and smokers. All radiographs were read by the same expert reader.

Results-Consistent with their less continuous and less intense exposure to asbestos, metal workers had: (a) far less frequent radiographic asbestosis (profusion score $\geqslant 1 / 0,17 \cdot 5 \% v 59.6 \%$ for insulators); (b) less severe radiographic asbestosis (only $1 \cdot 1 \%$ had scores $\geqslant 2 / 1 v$ $13 \cdot 3 \%$ of insulators); (c) a similar slope to that seen in insulators for the relation between FVC and profusion score when pleural thickening was absent; (d) less frequent pleural fibrosis (36\% v 75\%); and (e) less frequent restrictive impairment $(23 \% v 33 \%)$. In both insulators and metal workers, lung function was below normal even when lung fields were normal, FVC fell with increasing profusion, it was lower in smokers and in those with pleural thickening at comparable profusion scores, and there was no difference in FVC between scores $0 / 1$ and $1 / 0$.

Conclusion-The decrease in FVC with increasing profusion score in both workforces as well as the similar slopes for the relation between FVC and profusion score and the similar FVC at similar scores in the absence of pleural thickening confirm the ILO profusion score as an acceptable assessment of pulmonary fibrosis.

(Occup Environ Med 1996;53:808-812)

Keywords: spirometry; fibrosis; asbestos; International Labour Organisation classification
Of the many workforces exposed to asbestos in North America investigated by the Pulmonary/ Occupational Medicine Group at the Mount Sinai Medical Center in New York, the two largest have been insulators and sheet metal workers. We described the radiographic ${ }^{12}$ and spirometric findings in insulators ${ }^{3}$ and radiographic findings in metal workers. ${ }^{4}$ We then assessed, for insulators, the relation between the International Labour Organisation (ILO) profusion score of small irregular opacities as a radiographic index of interstitial fibrosis and the forced vital capacity (FVC) as a physiological index of interstitial fibrosis. ${ }^{5}$

Despite similar ages, durations of occupational exposure, and smoking histories, metal workers have radiographic interstitial fibrosis less often and less severely, consistent with a less intense exposure to asbestos, as may be expected from the nature of their work compared with insulators.

In this report, we describe the relation between profusion score and FVC in metal workers, compared with insulators. We considered the question whether the relations between the radiographic and physiological indices of interstitial fibrosis are different in these two workforces with similar demographic features but different intensities of exposure to asbestos.

\section{Methods}

With records from their international unions, both workforces were surveyed in many cities across North America by the same team with the same methods, insulators during 1983-4 and metal workers during 1986-7. Both surveys concentrated on workers with at least 20 years in the trade. Details of the surveys have been provided ${ }^{35}$ including confirmation that there was no bias towards more impaired subjects. ${ }^{5}$ Of the 1330 metal workers, $35(2 \cdot 6 \%)$ did not have complete spirometric information and are not included in this study. ${ }^{4}$

Spirometric methods have been fully described $^{35}$ and adhered to current guidelines ${ }^{6}$; at least three acceptable efforts were obtained on each subject. Predicted values were those published by this laboratory with the same equipment in a random sample of the population of a large industrial statenamely, Michigan. ${ }^{7}$ The Michigan predicted values are very similar to two widely used reference values, those of Crapo $\mathrm{et}^{\mathrm{al}} \mathrm{l}^{8}$ and those of Morris et al. ${ }^{9}$ Frequencies of abnormal values were calculated for FVC with the lower $95 \%$ confidence interval $(95 \% \mathrm{CI})$, and for forced 
expiratory volume in one second $\left(\mathrm{FEV}_{1}\right) / \mathrm{FVC}$ a conventional lower limit of 0.70 for ages $\leqslant 59$ years and 0.65 for ages $\geqslant 60$ years was used. (No subjects were younger than 30 years of age.) Also, mutually exclusive spirometric impairments were defined as follows ${ }^{3}$ : normal spirometry $=$ normal $F V C, F_{1}, \quad F_{1} V_{1} /$ FVC, and forced expiratory time (FET) $25 \%-75 \% \quad(\leqslant 0.78 \mathrm{~s}) ; \quad$ obstructive $=$ FVC normal, $\mathrm{FEV}_{1} / \mathrm{FVC}$ below limits already defined; restrictive $=$ FVC $<$ lower $95 \% \mathrm{CI}$, $\mathrm{FEV}_{1} / \mathrm{FVC}$ normal; small airways dysfunction $=$ FVC normal, $\mathrm{FEV}_{1} / \mathrm{FVC}$ normal, FET $25 \%-75 \%$ increased; and combined $=$ both FVC and $\mathrm{FEV}_{1} / \mathrm{FVC}$ decreased.

Never-smokers were defined ${ }^{35}$ as people who smoked less than one cigarette a day, had smoked $<10$ cigarettes a day for $<6$ months, or smoked only cigars and pipes, which are not inhaled. Current smokers exceeded these limits. Ex-smokers exceeded these limits and had discontinued smoking more than two years previously. For many statistical analyses, current and ex-smokers were combined (positive smoking history).

All radiographs were read with the latest (1980) ILO classification ${ }^{10}$ by the same senior expert (B) reader (RL), who has often served on international panels to standardise such readings. As the readings were made several years apart, the reader was aware of the occupation but not of the age, years from the start of exposure, or smoking status.

For statistical analyses, the 12 point ILO profusion score was compressed to seven points: $0 /-, 0 / 0=0,0 / 1=1,1 / 0=2,1 / 1=$ $3,1 / 2=4,2 / 1,2 / 2,2 / 3=5,3 / 2,3 /$ $3,3 /+=6$.

\section{STATISTICAL METHODS}

Fisher's exact test ${ }^{11}$ was used to test the equality of two proportions-for example, the proportion of metal workers with a certain characteristic $v$ proportion of insulators with the same characteristic. A two sample test ${ }^{11}$ was used for the comparison of two meansfor example, the mean FVC in metal workers $v$ the mean FVC in insulators. Linear regression $^{11}$ was used to relate FVC to profusion scores in each workforce, and in workers within each workforce with and without pleural abnormalities or a history of smoking. These models best considered the question which was one of the purposes of our study: whether a similar profusion score in differently exposed workers may be associated with a different effect on lung function.

Multiple regression methods, with SAS statistical software, ${ }^{12}$ related the outcome variable, $\%$ predicted FVC, to variables which were either primary or secondary measures of exposure. These variables were type of employment (insulators or metal workers), profusion score (ILO scores expressed on a seven point scale), radiographic pleural thickening (none or any), smoking history (never or ever), and the interactions between these variables. $F$ tests were used to test the significance of coefficients in the regression models. Models included (1) all workers and (2) those
Table 1 Years from the start of exposure to asbestos in the two workforces

\begin{tabular}{lcc}
\hline & $\begin{array}{l}\text { Metal workers } \\
n(\%)\end{array}$ & $\begin{array}{l}\text { Insulators } \\
n(\%)\end{array}$ \\
\hline$\leqslant 29 \mathrm{y}$ & $85(7)$ & $341(13)$ \\
$30-39$ & $624(48)$ & $1614(62)$ \\
$\geqslant 40 \mathrm{y}$ & $586(45)$ & $656(25)$ \\
Total & $1295(100)$ & $2611(100)$ \\
\hline
\end{tabular}

Table 2 Smoking status in the two workforces

\begin{tabular}{llr}
\hline & $\begin{array}{l}\text { Metal workers } \\
n(\%)\end{array}$ & $\begin{array}{l}\text { Insulators } \\
n(\%)\end{array}$ \\
\hline Non-smokers & $259(20)$ & $515(19 \cdot 7)$ \\
Current smokers & $310(24)$ & $875(33 \cdot 5)$ \\
Ex-smokers & $726(56)$ & $1221(46 \cdot 8)$ \\
\hline
\end{tabular}

without pleural abnormalities. However, there were only seven metal workers who did not have pleural thickening with profusion scores $>1 / 0$ (all of whom were smokers). This made model (2) unproductive.

\section{Results}

Although the two workforces have long durations of exposure and similar frequencies of smoking, tables 1 and 2 show that more metal workers had longer exposures and fewer were current smokers.

Table 3 and fig 1 show that the distribution of profusion scores was notably skewed towards the normal in metal workers: $71.4 \%$ of whom had a profusion score of $0 / 0 v 15.9 \%$ of insulators, whereas only $1 \cdot 1 \%$ had a profusion score $\geqslant 2 / 1 v 13.3 \%$ of insulators.

Table 3 Frequencies of profusion sources in the two workforces

\begin{tabular}{lll}
\hline & $\begin{array}{l}\text { Metal workers } \\
n(\%)\end{array}$ & $\begin{array}{l}\text { Insulators } \\
n(\%)\end{array}$ \\
\hline $0 / 0$ & $924(71 \cdot 4)$ & $414(15 \cdot 9)$ \\
$0 / 1$ & $145(11 \cdot 2)$ & $640(24 \cdot 5)$ \\
$1 / 0$ & $95(7 \cdot 3)$ & $456(17 \cdot 5)$ \\
$1 / 1$ & $101(7 \cdot 8)$ & $627(24 \cdot 0)$ \\
$1 / 2$ & $16(1 \cdot 2)$ & $127(4 \cdot 9)$ \\
$2 / 1$ & $6(0 \cdot 5)$ & $87(3 \cdot 3)$ \\
$2 / 2$ & $7(0 \cdot 5)$ & $143(5 \cdot 5)$ \\
$\geqslant 2 / 3$ & $1(0 \cdot 1)$ & $117(4 \cdot 5)$ \\
\hline
\end{tabular}

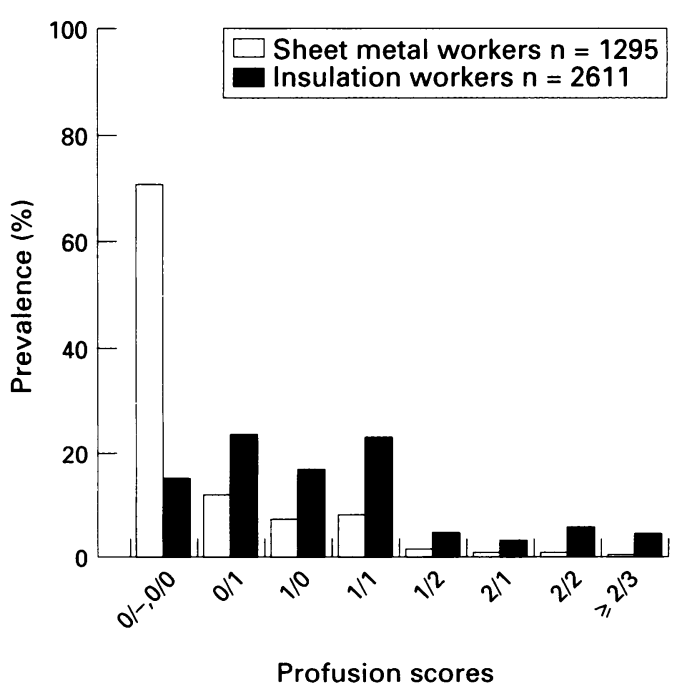

Distribution of profusion scores in the two workforces. 
Table 4 Mean (SEM) FVC as \% predicted by profusion score in the two workforces

\begin{tabular}{lcc}
\hline Profusion score & $\begin{array}{l}\text { Metal workers } \\
(n=1245)\end{array}$ & $\begin{array}{c}\text { Insulators } \\
(n=2611)\end{array}$ \\
\hline $0 /-, 0 / 0$ & $88 \cdot 0(0 \cdot 5)$ & $88 \cdot 0(0 \cdot 8)$ \\
$0 / 1$ & $86 \cdot 2(1 \cdot 5)$ & $85 \cdot 1(0 \cdot 6)$ \\
$1 / 0$ & $88 \cdot 0(1 \cdot 5)$ & $85 \cdot 0(0 \cdot 7)$ \\
$1 / 1$ & $84 \cdot 4(1 \cdot 6)$ & $81 \cdot 8(0 \cdot 6)$ \\
$1 / 2$ & $79 \cdot 3(3 \cdot 5)$ & $77 \cdot 7(1 \cdot 5)$ \\
$2 / 1-2 / 3$ & $72 \cdot 8(7 \cdot 9)$ & $74 \cdot 4(1 \cdot 0)$ \\
$\geqslant 3 / 2$ & + & $67 \cdot 5(2 \cdot 1)$ \\
Intercept & $88 \cdot 13(0 \cdot 52)$ & $88 \cdot 77(0 \cdot 53)$ \\
Profusion & $-1.50(0 \cdot 41)$ & $-2 \cdot 73(0 \cdot 19)$ \\
$\quad$ coefficient & $(\mathrm{P} \leqslant 0 \cdot 0003)$ & $(\mathrm{P} \leqslant 0 \cdot 0001)$ \\
\hline
\end{tabular}

$\star P$ value for difference between coefficients $\leqslant 0 \cdot 006$. $t_{\mathrm{n}}=1$, not reported.

Table 5 Mean (SEM) FVC as \% predicted by profusion score in metal workers and insulators: non-smokers $\mathrm{v}$ smokers

\begin{tabular}{|c|c|c|c|c|}
\hline \multirow[b]{2}{*}{ Profusion score } & \multicolumn{2}{|l|}{ Non-smokers } & \multicolumn{2}{|l|}{ Smokers } \\
\hline & $\begin{array}{l}\text { Metal workers } \\
(n=259)\end{array}$ & $\begin{array}{l}\text { Insulators } \\
(n=515)\end{array}$ & $\begin{array}{l}\text { Metal workers } \\
(n=1036)\end{array}$ & $\begin{array}{l}\text { Insulators } \\
(n=2096)\end{array}$ \\
\hline $0 /-, 0 / 0$ & $91 \cdot 0(1 \cdot 1)$ & $90 \cdot 4(1 \cdot 4)$ & $87 \cdot 1(0 \cdot 6)$ & $86.9(0.9)$ \\
\hline $0 / 1$ & $88 \cdot 0(3 \cdot 0)$ & $87 \cdot 2(1 \cdot 2)$ & $85 \cdot 8(1 \cdot 7)$ & $84 \cdot 3(0 \cdot 7)$ \\
\hline $1 / 0$ & $92 \cdot 7(3 \cdot 4)$ & $86 \cdot 1(1 \cdot 8)$ & $87 \cdot 5(1 \cdot 6)$ & $84 \cdot 7(0 \cdot 8)$ \\
\hline $1 / 1$ & $90.9(5.4)$ & $83.5(1.7)$ & $83.6(1.7)$ & $81.5(0 \cdot 7)$ \\
\hline $1 / 2$ & $t$ & $83.0(5 \cdot 2)$ & $79 \cdot 7(3 \cdot 7)$ & $76.9(1.5)$ \\
\hline $2 / 1-2 / 3$ & $84.3(10.5)$ & $77 \cdot 2(4 \cdot 3)$ & $69 \cdot 4(9 \cdot 7)$ & $74 \cdot 3(1 \cdot 0)$ \\
\hline$\geqslant 3 / 2$ & & $66.7(10 \cdot 0)$ & $t$ & $67 \cdot 5(2 \cdot 1)$ \\
\hline Áll & $90 \cdot 7$ & $86 \cdot 5$ & $86 \cdot 3$ & $81 \cdot 8$ \\
\hline Intercept & $90.97(1.05)$ & $90 \cdot 25(1 \cdot 11)$ & $87 \cdot 31(0 \cdot 59)$ & $88 \cdot 08(0 \cdot 61)$ \\
\hline $\begin{array}{l}\text { Profusion } \\
\text { coefficient }\end{array}$ & $\begin{array}{l}-0.83(1.11) \\
0.44\end{array}$ & $-2.38(0.53)$ & $-1.43(0.45)$ & $-2.65(0.21)$ \\
\hline$P$ value & $0 \cdot 44$ & $0 \cdot 0001$ & 0.002 & $0 \cdot 0001$ \\
\hline
\end{tabular}

$t_{n}=1$, not reported

Table 6 Mean (SEM) FVC as \% predicted by profusion score in metal workers and insulators in the presence or absence of pleural thickening

\begin{tabular}{|c|c|c|c|c|}
\hline \multirow[b]{2}{*}{ Profusion score } & \multicolumn{2}{|c|}{ Pleural thickening absent } & \multicolumn{2}{|c|}{ Pleural thickening present } \\
\hline & $\begin{array}{l}\text { Metal workers } \\
(n=820)\end{array}$ & $\begin{array}{l}\text { Insulators } \\
(n=722)\end{array}$ & $\begin{array}{l}\text { Metal workers } \\
(n=468)\end{array}$ & $\begin{array}{l}\text { Insulators } \\
(n=1889)\end{array}$ \\
\hline $0 /-, 0 / 0$ & $89 \cdot 5(0 \cdot 6)$ & $89 \cdot 8(1 \cdot 0)$ & $84 \cdot 2(1 \cdot 0)$ & $86 \cdot 2(1 \cdot 1)$ \\
\hline $0 / 1$ & $85 \cdot 4(2 \cdot 0)$ & $89.9(1.0)$ & $87 \cdot 2(2 \cdot 1)$ & $82.6(0.8)$ \\
\hline $1 / 0$ & $89.6(2 \cdot 4)$ & $90 \cdot 6(1 \cdot 3)$ & $86.8(1.9)$ & $83.0(0.9)$ \\
\hline $1 / 1$ & $86.5(3.0)$ & $88.5(1.5)$ & $83.3(1.9)$ & $80 \cdot 2(0 \cdot 7)$ \\
\hline $1 / 2$ & $85 \cdot 3(8 \cdot 7)$ & $83 \cdot 7(3.3)$ & $76 \cdot 6(3 \cdot 2)$ & $76 \cdot 8(1 \cdot 6)$ \\
\hline $2 / 1-2 / 3$ & $75 \cdot 2(26 \cdot 6)$ & $78.9(3.0)$ & $72 \cdot 1(7 \cdot 8)$ & $73 \cdot 8(1 \cdot 1)$ \\
\hline$\geqslant 3 / 2$ & & $66 \cdot 3(7 \cdot 7)$ & $t$ & $67 \cdot 7(2 \cdot 2)$ \\
\hline All & $88 \cdot 9(0 \cdot 6)$ & $88.9(0 \cdot 6)$ & $84.3(0 \cdot 7)$ & $80 \cdot 4(0 \cdot 4)$ \\
\hline Intercept & $89.36(0.63)$ & $91.34(0.85)$ & $85.2(0.93)$ & $86.5(0.66)$ \\
\hline \multicolumn{5}{|l|}{ Profusion } \\
\hline coefficient & $-1.26(0.68)$ & $-1.62(0.41)$ & $-0.85(0.55)$ & $-2.48(0.22)$ \\
\hline \multirow{2}{*}{$\begin{array}{l}\text { P value } \\
\text { P value of } \\
\text { metal workers } \\
v \text { insulators }\end{array}$} & 0.06 & 0.0001 & $0 \cdot 12$ & 0.0001 \\
\hline & \multicolumn{2}{|c|}{ NS } & \multicolumn{2}{|c|}{0.005} \\
\hline
\end{tabular}

$t_{\mathrm{n}}=1$, not reported.

Table 4 shows that FVC fell with increasing profusion score in metal workers (as has been shown in insulators ${ }^{5}$ ) with a $P=0.0003$ for the overall relation. Although no one score had a significantly different FVC from an adjacent score, the FVC for readings $\geqslant 1 / 2$ was significantly lower than the FVC for scores $\leqslant 1 / 1$ (P $\leqslant 0.006)$. However, the slope of the decrease in FVC was significantly less in metal workers than in insulators $(P \leqslant 0.0006)$.

As documented for insulators, the FVC in metal workers was no lower for a score of $1 / 0$ than for a score of $0 / 1$, and unequivocally normal lung fields (scores $0 /-$ or $0 / 0$ ) were associated with a considerably lower FVC $(88.0 \%$ of predicted) than the expected value of $100 \%$ of predicted.

Table 5 shows the relation between FVC and profusion score in the two workforces divided into non-smokers and smokers. Values for FVC in metal workers who did not smoke showed no relation to profusion score in the narrow range of scores found in non-smokers; only four metal workers who did not smoke had scores $>1 / 1$. Values of FVC in smokers were consistently lower than those of non-smokers, as has been reported for insulators. The difference between all metal workers who smoked $(86.3 \%$ of predicted) and did not smoke ( $90.7 \%$ of predicted) was $4.4 \%$ of predicted, very similar to the difference of $4.7 \%$ of predicted previously reported for insulators.

The difference in FVC between metal workers and insulators is significant both for nonsmokers $(90.7 \% \quad v \quad 86.5 \%$ of predicted; $\mathrm{P} \leqslant 0.0008)$ and for smokers (86.3\% v 81.8\%, $P \leqslant 0.0001)$.

Table 6 shows the relation between FVC and profusion score in the absence and in the presence of pleural thickening. Values for FVC were consistently lower at each profusion score (with the exception of $0 / 1$ ) in the presence of pleural thickening, as has been reported for insulators. ${ }^{5}$ The difference in FVC between all metal workers with pleural thickening $(84.4 \%$ of predicted) and all those without pleural thickening $(88.9 \%$ of predicted) was $4.5 \%$ of predicted $(v 8.5 \%$ of predicted reported for insulators). In the absence of pleural thickening, metal workers and insulators showed no difference in the decrease of the slope in FVC with increasing score, whereas a significant difference was noted between metal workers and insulators with pleural thickening $(P \leqslant 0.005)$.

Table 7 examines the relation of FVC to profusion score depending on duration of exposure. When lung fields were unequivocally normal (profusion $0 /$ - or $0 / 0$ ), both metal workers and insulators showed smaller FVC values as duration increased, a finding which cannot be attributed to aging alone as the FVC values were adjusted for age. For all workers with $\geqslant 40$ years since the start of exposure, insulators had significantly lower FVC values than metal workers at profusion scores $0 / 0$ to $1 / 1$

Table 7 Mean (SEM) FVC as \% predicted by profusion score in metal workers, and insulators, depending on years from start of exposure

\begin{tabular}{|c|c|c|c|c|c|c|c|c|c|c|c|c|}
\hline \multirow{3}{*}{$\begin{array}{l}\text { Profusion } \\
\text { score }\end{array}$} & \multirow{2}{*}{\multicolumn{2}{|c|}{$\frac{<29}{\text { Metal workers }}$}} & \multirow{2}{*}{\multicolumn{2}{|c|}{ Insulators }} & \multicolumn{4}{|c|}{$30-39$} & \multirow{2}{*}{\multicolumn{2}{|c|}{$\begin{array}{l}\geqslant 40 \\
\text { Metal workers }\end{array}$}} & & \\
\hline & & & & & \multicolumn{2}{|c|}{ Metal workers } & \multicolumn{2}{|c|}{ Insulators } & & & \multicolumn{2}{|c|}{ Insulators } \\
\hline & $n$ & mean (SEM) & $n$ & mean (SEM) & $n$ & mean (SEM) & $n$ & mean (SEM) & $n$ & mean (SEM) & $n$ & mean (SEM) \\
\hline $0 / 0$ & 64 & $93.7(1.9)$ & 94 & $92.9(1.6)$ & 458 & $88.7(0.7)$ & 250 & $88 \cdot 2(1 \cdot 0)$ & 402 & $86 \cdot 2(0 \cdot 8)$ & 70 & $80 \cdot 6(1.9)$ \\
\hline $0 / 1$ & 9 & $88 \cdot 8(7 \cdot 8)$ & 119 & $88.9(1.3)$ & 70 & $85 \cdot 8(2 \cdot 1)$ & 391 & $85.5(0.8)$ & 66 & $86 \cdot 2(2 \cdot 1)$ & 130 & $80.3(1.5)$ \\
\hline $1 / 0$ & 7 & $87.6(3 \cdot 1)$ & 59 & $89.6(2.0)$ & 39 & $88.9(2 \cdot 1)$ & 293 & $85.8(0.9)$ & 49 & $87 \cdot 3(2 \cdot 4)$ & 104 & $80 \cdot 0(1 \cdot 6)$ \\
\hline $1 / 1$ & & $t$ & 53 & $84 \cdot 6(2 \cdot 0)$ & 43 & $88 \cdot 1(2 \cdot 0)$ & 397 & $83.6(0.8)$ & 55 & $81 \cdot 1(2 \cdot 5)$ & 177 & $77 \cdot 0(1 \cdot 2)$ \\
\hline $1 / 2$ & & $\dot{t}$ & 8 & $74 \cdot 9(4 \cdot 3)$ & 8 & $83.7(5.9)$ & 76 & $80 \cdot 8(1.8)$ & 6 & $72 \cdot 7(4 \cdot 0)$ & 43 & $72 \cdot 8(2 \cdot 7)$ \\
\hline $2 / 1-2 / 3$ & & $\dot{t}$ & 7 & $73 \cdot 2(4 \cdot 4)$ & 5 & $65.0(13 \cdot 8)$ & 156 & $76.5(1.4)$ & 8 & $77 \cdot 7(9 \cdot 8)$ & 106 & $71.6(1.5)$ \\
\hline$\geqslant 3 / 2$ & & $t$ & & $t$ & & $t$ & 51 & $68 \cdot 2(2 \cdot 5)$ & & $t$ & 26 & $66 \cdot 5(3 \cdot 8)$ \\
\hline
\end{tabular}

$t_{n} \leqslant 4$, not reported. 
Table 8 Multiple regression analysis for all workers (dependent variable is FVC \% predicted)

\begin{tabular}{lcc}
\hline Variables & Coefficient (SEM) & P value \\
\hline Intercept & $91.7(0.77)$ & - \\
Profusion & $-0.55(0.49)$ & 0.26 \\
Pleural $\dagger$ & $-3.56(1.00)$ & 0.0001 \\
Smoking $\neq$ & $-3.30(0.65)$ & 0.0001 \\
Occupation & $2.39(0.97)$ & 0.01 \\
Profusion $\times$ occupation & $-1.13(0.47)$ & 0.01 \\
Pleural thickening $\times$ occupation & $-1.91(1.29)$ & 0.14 \\
Pleural thickening $\times$ profusion & $-0.58(0.41)$ & 0.16 \\
\hline
\end{tabular}

$\star^{*} 0=0 /-, 0 / 0,1=0 / 1,2=1 / 0,3=1 / 1,4=1 / 2, \quad 5=2 / 1-2 / 3,6=3 / 2-3 /+$

to $=$ None, $1=$ present.

$\dagger 0$
$\neq 0$

$\S 0=$ Metal workers, 1 = insulators.

Table 9 Categories of impairment in metal workers, by smoking category

\begin{tabular}{llcl}
\hline & $\begin{array}{l}\text { All } \\
(n=1295) \\
n(\%)\end{array}$ & $\begin{array}{l}\text { Non-smokers } \\
(n=259) \\
n(\%)\end{array}$ & $\begin{array}{l}\text { Smokers } \\
(n=1036) \\
n(\%)\end{array}$ \\
\hline Normal & $459(35)[29]$ & $131(51)[44]$ & $328(32)[25]$ \\
Obstructive & $97(7)[10]$ & $8(3)[3]$ & $89(9)[11]$ \\
Restrictive & $303(23)[33]$ & $63(24)[31]$ & $240(23)[33]$ \\
Small airways & $311(24)[18]$ & $52(20)[19]$ & $259(25)[17]$ \\
Combined & $125(10)[11]$ & $5(2)[3]$ & $120(12)[13]$ \\
Decreased FEV $/$ FVC & $222(17)[21]$ & $13(5)[6]$ & $209(20)[25]$ \\
Decreased FVC & $428(33)[44]$ & $68(26)[33]$ & $360(34)[46]$ \\
\hline
\end{tabular}

*Frequencies in [] are for insulators, $(n=2611){ }^{3}$

(there were few metal workers with scores $>1 / 1)$.

Because of the number of variables involved in attempting to answer the question whether a similar profusion score is associated with a similar effect on lung function (as assessed by FVC), multiple regression analysis was performed. Table 8 shows the results for all workers. To remove the confounding effect of pleural thickening, only those workers without pleural thickening were modelled. However, there were only seven metal workers with scores $>1 / 0$ (all of whom were smokers), limiting this model. When all workers (those with and those without pleural thickening) were included (table 8), there was a highly significant effect on FVC for smoking ( $P \leqslant 0.0001$ ), a highly significant effect for pleural thickening $(P \leqslant 0.0001)$, a significant effect for insulators $v$ metal workers, and a significant effect for profusion in insulators $(P \leqslant 0 \cdot 01)$. In this model,

Table 10 Categories of impairment in metal workers in the presence and absence of pleural thickening

\begin{tabular}{lll}
\hline & $\begin{array}{l}\text { Pleural thickening absent } \\
(n=827)\end{array}$ & $\begin{array}{l}\text { Pleural thickening present } \\
(n=468) \\
n(\%)\end{array}$ \\
\hline Normal & $313(38)[41]$ & $147(31)[24]$ \\
Obstructive & $68(8)[10]$ & $29(6)[10]$ \\
Restrictive & $164(20)[22]$ & $139(30)[37]$ \\
Small airways & $207(25)[20]$ & $104(22)[17]$ \\
Combined & $76(9)[7]$ & $49(10)[13]$ \\
Decreased FEV $/$ FVC & $144(17)[17]$ & $78(17)[22]$ \\
Decreased FVC & $240(28)[29]$ & $188(39)[49]$
\end{tabular}

${ }^{\star}$ Frequencies in [] are for insulators. ${ }^{3}$

Table 11 Categories of impairment (\%) in metal workers with increasing profusion scores

\begin{tabular}{lcccccc}
\hline & $\begin{array}{l}0 / 0 \\
(n=924)\end{array}$ & $\begin{array}{l}0 / 1 \\
(n=145)\end{array}$ & $\begin{array}{l}1 / 0 \\
(n=95)\end{array}$ & $\begin{array}{l}1 / 1 \\
(n=101)\end{array}$ & $\begin{array}{l}1 / 2 \\
(n=16)\end{array}$ & $\begin{array}{l}\geqslant 2 / 1 \\
(n=14)\end{array}$ \\
\hline Normal & 38 & 32 & 32 & 29 & 13 & 0 \\
Obstructive & 7 & 5 & 11 & 12 & 0 & 14 \\
Restrictive & 22 & 30 & 26 & 21 & 50 & 43 \\
Small airways & 25 & 26 & 22 & 20 & 13 & 28 \\
Combined & 9 & 8 & 9 & 19 & 25 & 14 \\
Decreased & 16 & 13 & 20 & 31 & 25 & 28 \\
FEV $/$ FVC & 16 & 38 & 35 & 40 & 75 & 57 \\
Decreased FVC & 31 & & & &
\end{tabular}

each increment in the seven point scale of profusion scores was associated with a decrease in FVC of $0.55 \%$ of the predicted value in metal workers and $1.68 \%$ in insulators, reflecting the confounding effect of pleural thickening in the insulators.

Tables 9 and 10 show the contrasting prevalences of spirometric impairment for insulators and metal workers. For all workers, the prevalence of restriction was greater in insulators (33\% v 23\%, $\mathrm{P} \leqslant 0.011$ ), whereas the prevalence of obstruction was slightly greater $(10 \% v$ $7 \%$ ) and dysfunction of isolated small airways was less $(18 \% v 24 \%, P \leqslant 0.001)$. This pattern was found in both smokers and non-smokers, and in those with and without pleural thickening.

Differences in frequencies of spirometric impairment were found between metal workers who were non-smokers and smokers (table 10) for normal lung function $(51 \% v 32 \%, \mathrm{P}$ $\leqslant 0.001)$, obstructive ( $3 \% v 9 \%, \mathrm{P} \leqslant 0.001)$, combined $(2 \% v 12 \%, P \leqslant 0.001)$, decreased $\mathrm{FEV}_{1} / \mathrm{FVC}(5 \% \quad v 20 \%, \mathrm{P} \leqslant 0.001)$, and decreased FVC $(26 \% v 34 \% \mathrm{P} \leqslant 0.010)$. The frequency of restrictive impairment was similar (23\% v 24\%).

Restriction was more common in metal workers with pleural thickening (30\% v 20\%, table 10) but obstruction and dysfunction of isolated small airways were not.

As profusion increased within the low range of scores in metal workers (only $1 \cdot 1 \%$ had scores $>2 / 1$ ), the frequency of normal spirometric function declined (table 11). The frequency of restriction and of decreased FVC increased with scores $>1 / 1 ; 67 \%$ of subjects with scores $>1 / 1$ had a decreased FVC. On the other hand, about $80 \%$ of metal workers with decreased FVC had normal lung fields on radiographic examination (profusion scores $0 /-$, $0 / 0$, or $0 / 1)$. This finding was more likely in non-smokers $(61$ of $68,90 \%)$ than in smokers (273 of $360,76 \% \mathrm{P} \leqslant 0.010)$.

\section{Discussion}

Several investigations have considered the relation between radiographic interstitial pulmonary fibrosis and spirometric lung function in people exposed to asbestos. In the largest of these groups in a single trade, the 2611 insulators who are part of this comparative study, lung function declined with increasing profusion of irregular opacities as scored by the ILO classification. ${ }^{5}$ In this paper, we have compared these insulators with 1295 sheet metal workers of similar age, duration of exposure, and smoking habits. Frequency and severity of pulmonary fibrosis were far less in metal workers, consistent with their less intense and less frequent exposure to asbestos: $71 \cdot 4 \%$ of metal workers had scores of $0 /-$ or $0 / 0(v 15.9 \%$ of insulators), whereas only $1 \cdot 1 \%$ had scores $\geqslant 2 / 1$ ( $v 13.3 \%$ of insulators).

We have previously compared the radiographic frequency and extent, as well as the physiological effects, of pleural fibrosis related to asbestos in metal workers $v$ insulators. ${ }^{13}$ Pleural fibrosis was far less frequent in metal 
workers, $36 \% v 75 \%$ than in insulators, and it was less extensive with a quantitative index. The functional impact of pleural fibrosis was also less, the decrement in FVC being smaller with increasing index, even in the absence of parenchymal disease. (The FVC was $85 \%$ of predicted in metal workers $v 80 \%$ of predicted in insulators at index $10-12$ and $80 \% v 76 \%$ of predicted at index 13-15). Factors contributing to this difference in the functional impact of pleural fibrosis in the two workforces included a smaller proportion of cases of diffuse pleural fibrosis in metal workers $(9 \% v 18 \%)$. As in insulators, there was a relation between severity of circumscribed pleural fibrosis and decrease in FVC but no such relation for diffuse pleural fibrosis.

Most findings in metal workers reported in this paper confirm the observations made in insulators:

(1) The FVC fell significantly with increasing profusion. The slope of this decline was similar in the two workforces in the absence of pleural thickening (table 6) but was different when pleural thickening was present, most likely reflecting the greater prevalence and severity of pleural thickening in insulators. Multiple regression analysis (table 8) showed the interaction of profusion with occupation (the greater effect of profusion on FVC in insulators in the entire study population) and suggested interactions between pleural thickening and occupation as well as between pleural thickening and profusion.

(2) Lung function was below normal even when lung fields were normal, adding evidence to an effect of the asbestos not apparent on standard films. It is of interest that at profusion scores $0 /-$ and $0 / 0$, irrespective of smoking or pleural thickening, metal workers and insulators have remarkably similar FVC values. This may suggest a similar impact from a lung burden of asbestos fibres which does not result in radiographically detectable interstitial fibrosis.

(3) There was no difference in lung function between intermediate scores $0 / 1$ and $1 / 0$, suggesting that these two readings, made by an experienced certified reader, do not distinguish severity of lung disease (or its presence from its absence).

(4) The FVC was consistently lower in smokers with comparable profusion.

(5) The FVC was lower in the presence of pleural thickening, although less so than in insulators, reflecting both the less severe pleural thickening in metal workers and its smaller functional impact. ${ }^{13}$

Prevalence of restrictive impairment was less in metal workers than in insulators $(23 \% v$ $33 \%$ ), as was the prevalence of decreased FVC (33\% v 44\%), reflecting less burden of disease related to asbestos in metal workers. As in insulators, obstruction (3\%) and decreased $\mathrm{FEV}_{1} / \mathrm{FVC}(5 \%)$ were uncommon in nonsmokers. Restriction by itself was not more common in smokers, although obstruction and combined impairment were.

The differences in exposure, and in its effects, in the two workforces permitted us to consider the question whether a similar radi- ographic score for parenchymal fibrosis may be associated with a different reduction in FVC.

Both linear and multiple regression analysis showed a significantly smaller decrease in FVC with each increment in profusion score in metal workers than the insulators. This finding was noted in both smokers and non-smokers, suggesting that it was related to the differences in exposure to asbestos rather than to a fibrogenic interaction between smoking and exposure. It may be that the greater decrement in FVC with increasing profusion of parenchymal infiltrates found in insulators with pleural thickening compared with metal workers with pleural thickening is related to an effect of the pleural thickening, as it is more extensive in insulators. This suggestion is consistent with the similar slope in FVC between metal workers and insulators in the absence of pleural thickening. However, there were simply too few metal workers without pleural thickening who had higher profusion scores to allow comparison with insulators over the range of scores found in insulators.

\section{Conclusion}

The decrease in FVC with increasing profusion score in both workforces as well as the similar slopes for the relation between FVC and profusion score and the similar FVC at similar scores in the absence of pleural thickening confirm the ILO profusion score as an acceptable assessment of pulmonary fibrosis.

Supported in part by the National Institute of Environmenta Health Science Center, grant ES 00928 .

1 Lilis R, Selikoff IJ, Lerman Y, Gelb SK. Asbestosis: interstitial pulmonary fibrosis and pleural fibrosis in a cohor stitial pulmonary fibrosis and pleural fibrosis in a cohort
of asbestos insulation workers: influence of cigarette of asbestos insulation workers: influen
smoking. $A m \mathcal{F}$ Ind Med 1986;10:459-70.

2 Lilis R, Miller A, Godbold J, Chan E, Selikoff IJ Radiographic abnormalities in asbestos insulators: effects of duration from onset of exposure and smoking: relationships of dyspnea with parenchymal and pleural fibrosis. Am F Ind Med 1991;20:1-15.

3 Miller A, Lilis R, Godbold J, Chan E, Wu X, Selikoff IJ Spirometric impairments in long-term insulators. Relationships to duration of exposure, smoking and radiRelationships to duration of exposure, smoking

4 Selikoff IJ, Lilis R. Radiological abnormalities among sheet metal workers in the construction industry in the United States and Canada: relationship to asbestos exposure. States and Canada: relationship
Arch Environ Health 1991;46:30-6.

5 Miller A, Lilis R, Godbold J, Chan E, Selikoff IJ. Relationship of pulmonary function to radiographic interstitia fibrosis in 2611 long term asbestos insulators: an assessment of the ILO profusion score. Am Rev Respir Dis 1992;145:263-70.

6 American Thoracic Society, Standardization of spirometry1987 update. Am Rev Respir Dis 1987;136:1285-98.

7 Miller A, Thornton JC, Warshaw R, Bernstein J, Teirstein AS, Selikoff IJ. Mean and instantaneous expiratory flows, FVC and $\mathrm{FEV}_{1}$ : prediction equations for nonsmokers FVC and $\mathrm{FEV}_{1}$ : prediction equations for nonsmokers and smokers from a random sample of Michigan, a large industrial state. Bull Physiopathol Respir 1986;22:589-97. Crapo RO, Morris AH, Gardner RM. Reference spirometric
values using techniques and equipment that meet ATS values using techniques and equipment that meet ATS
recommendations. Am Rev Respir Dis 1981;123:659-64. 9 Morris JF, Koski A, Johnson LC. Spirometric standards for healthy nonsmoking adults. Am Rev Respir Dis 1971;103 $57-67$.

10 International Labour Office. Guidelines for use of the ILO international classification of radiographs of pneumoconioses. Geneva: ILO, 1980 (Occupational Safety and Health Series No 22, revised)

11 Altman DG. Practical statistics for medical research. New York: Chapman and Hall, 1991.

12 SAS Institute. SAS/STAT user's guide, version 6, 4th ed. Cary, NC: SAS Institute, 1989.

13 Lilis R, Miller A, Godbold J, Benkert S, Wu X, Selikoff IJ. Comparative quantitative evaluation of pleural fibrosis and its effects on pulmonary function in two large asbestos-exposed occupational groups-insulators and asbeet metal workers. Environ Res 1992;59:49-66. 